\title{
Evaluation of the Effect of Air Polishing With Different Abrasive Powders on the Roughness of Implant Abutment
} Surface: An In Vitro Study

Beatriz Rosa Biazussi, $\mathrm{DDS}^{1} \dagger$

Vittoria Perrotti, DDS, $\mathrm{PhD}^{2 *}+$

Camillo D'Arcangelo, DDS ${ }^{2}$

Carlos Nelson Elias, $\mathrm{MSc}^{3}$

Marco Aurelio Bianchini, DDS ${ }^{1}$

Margherita Tumedei, DDS ${ }^{2}$

Diego Klee de Vasconcellos, DDS ${ }^{1}$

The aim of this in vitro study was to evaluate the effect of air polishing on the implant abutment surface using different abrasive powders: sodium bicarbonate and amino acid glycine. Fifteen grade III machined surface titanium disks with 8-mm diameter and 2-mm thickness were divided in 3 groups of 5 samples each and subjected to air polishing for 20 seconds with an Ultrajet Flex air-abrasive device and a distinct prophylaxis protocol: air and water (G1); air, water, and sodium bicarbonate (G2); and air, water; and amino acid glycine (G3). After the air polishing, the average roughness $(\mathrm{Ra})$ of the samples was measured using an optical profilometer, and the obtained data were statistically analyzed. We found that G1 and G3 had similar Ra, while Ra values for G2 were significantly higher. This study demonstrated that air-polishing powders containing glycine had less of an effect on the roughness of the surface of titanium disks compared with sodium bicarbonate powders. Future in vivo studies will be conducted to investigate the clinical relevance of the present results.

Key Words: abutments, air polishing, glycine powder, roughness, sodium bicarbonate

\section{INTRODUCTION}

$\mathrm{T}$ he primary etiologic factor of peri-implant disease is bacterial biofilm, which leads to inflammation of the peri-implant tissues with bleeding on probing, and bone loss around an osseointegrated implant in function. ${ }^{1}$ Mombelli and Lang $^{2}$ stated that the essential condition for success in the treatment of peri-implantitis is decontamination of the implant surface by eliminating bacteria and toxins and removing supra- and subgingival biofilm. ${ }^{2}$ The rough surfaces could represent a key point in bacterial biofilm formation, especially in the transmucosal area of the fixture interface. $^{3}$ Commercially available titanium abutments present an approximate roughness ( $\mathrm{Ra}$ ) of $0.20 \mu \mathrm{m}$ that has been demonstrated to enable good soft-tissue adhesion and scarce bacterial colonization in the oral cavity. ${ }^{4,5}$

Currently, different substances and techniques could be used to decontaminate implant surfaces, such as tetracycline

\footnotetext{
${ }^{1}$ Universidade Federal de Santa Catarina, Campus Reitor João David Ferreira Lima, Florianópolis, Sants Catarina, Brazil.

${ }^{2}$ Department of Medical, Oral, and Biotechnological Sciences, University of Chieti-Pescara, Chieti, Italy.

${ }^{3}$ Military Institute of Engineering, Rio de Janeiro, Rio de Janeiro, Brazil.

* Corresponding author, e-mail: v.perrotti@unich.it

† These two authors contributed equally.

https://doi.org/10.1563/aaid-joi-D-18-00156
}

paste, citric acid in different concentrations, chlorhexidine, hydrogen peroxide, sodium bicarbonate jets, ultrasound, and removal of the exposed threads of the implant or implantoplasty. ${ }^{6}$ The abrasive air-jet system has been found to be a valuable treatment tool in plaque removal because it causes little damage to the implant surface. ${ }^{7}$ Air polishing using glycine and sodium bicarbonate powder seems to be safe for professional oral hygiene of titanium dental implants, although acid-etched abutments further treated with bicarbonate harbored more salts; this might indicate greater plaque accumulation during clinical function. ${ }^{8}$ On the contrary, blasting abrasive powders demonstrated effectiveness in the debridement and surface decontamination of titanium implants; their use was associated with surface changes influenced by the powder composition and the size and nature of the particles. ${ }^{9}$ Air polishing has been found to increase the surface roughness of dental restorations, enhancing bacterial adhesion. ${ }^{10}$ Airflow devices with abrasive powders have been shown to be a reasonable technique for removing biofilm in difficult-to-access areas compared with conventional mechanical techniques (plastic curettes or ultrasound). ${ }^{11}$ Usually, the abrasive powder of choice is sodium bicarbonate $(\mathrm{NaCOH} 3)$, which has been demonstrated to be more effective than manual instrumentation for removing deposits of subgingival plaque. ${ }^{12}$ Treatment with sodium bicarbonate on titanium surfaces does not significantly decrease adhesion of the 
fibroblasts. ${ }^{13}$ Clinically, these findings indicated that the use of bicarbonate does not indicate reduced biocompatibility of the surfaces. $^{14}$

To limit abrasion and make the blasting approach potentially suitable for removing biofilms on root surfaces, some researchers suggested replacing sodium bicarbonate with an amino acid glycine powder. ${ }^{2,15}$ Glycine is a nonessential amino acid, with one of the simplest structures among amino acids; it is soluble in water and fully biocompatible. The choice of glycine is due to its physical properties-it has very fine, rounded particles with little hardness. ${ }^{16}$ Chairay et al ${ }^{17}$ stated that special glycine-based powders demonstrated less abrasive potential than bicarbonate on the surfaces of the teeth and implants. Indeed, in contrast to sodium bicarbonate, the glycine particle size is less than $63 \mu \mathrm{m}$, making this powder ideal to be used along the gingival margins and deep subgingival pockets. ${ }^{4}$ The particle size of glycine is 4 times smaller than the sodium bicarbonate particles ${ }^{15}$ and, for that reason, can cause less trauma to the gingival epithelium, teeth, and implant surfaces.

In addition, the research of Sahm et $\mathrm{al}^{18}$ indicated that oral hygiene associated with glycine powder prophylaxis led to a significant reduction in probe depth compared with the group with oral hygiene associated with curette instrumentation. Finally, based on the literature review by Graumann et al, ${ }^{19}$ glycine-based powders showed many more advantages compared with other commercially available powders (sodium bicarbonate, aluminum oxide, calcium phosphosilicate, and sodium) showing less gingival erosion and creating minimal defects in restorations, teeth, and implant structures.

The present study hypothesized that no difference in surface roughness occurs after air-polish treatment with different abrasive powers. Therefore, the present study aimed to evaluate in vitro the effect of air polishing using 2 abrasive powders, sodium bicarbonate and glycine amino acid, applied for prophylaxis on the roughness of the surface of implant abutments.

\section{Methods}

\section{Sample size}

A power analysis was performed for the primary outcome variable, titanium surface roughness, to determine any difference between the experimental treatments on the samples. The calculation was performed by $\mathrm{G}^{*}$ Power 3.0 software (University of Kiel, Kiel, Germany), assuming a size treatment effect $(f=0.93)$, a power of 0.80 , an $\alpha$ significance level of 0.05 , and 3 experimental conditions; the power analysis resulted in a total sample size of 15 samples.

\section{Procedure}

Fifteen machined surface CP grade III titanium disks $8 \mathrm{~mm}$ in diameter and 2-mm thick were used as test specimens (the same surface treatment processes for prosthetic abutments).

The specimens were divided into the following 3 groups, each containing 5 disks, according to the type of abrasive product used for prophylaxis:

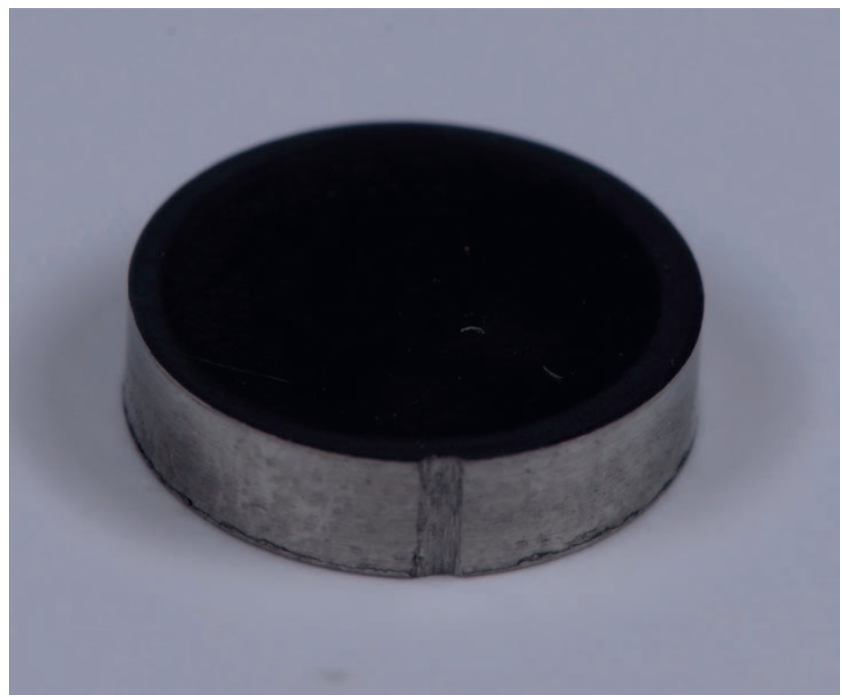

FigURE 1. Grade III titanium specimens.

G1: water and air

G2: water, air, and sodium bicarbonate (Cleaning Powder, Kavo, Biberach, Germany)

G3: water, air, and glycine (Clinpro Prophy Powder, 3M ESPE, Seefeld, Germany)

The device used for blasting was the Ultrajet Flex (Kavo), handled and calibrated according to the manufacturer's recommendations. Prior to blasting, a notch was made on the side of the specimens with a carborundum disk (Figure 1). For uniform blasting, with no change in distances or variations of the blasting site on the test specimens, a device was created so that the disk was positioned at a distance of $4 \mathrm{~mm}$ from the instrument nozzle. A mold with condensation silicone (Zetaplus, Zhemark, Badia Polesine, Italy) was created to fix the specimens, adding a marking that allowed alignment with the disk. The mold was secured to the base of the device so that the disks were individually positioned. The Ultrajet Flex was attached to the device so that there was no movement during the blasting; the tip was positioned $90^{\circ}$ to the surface of the specimens (Figure 2). The blasting time, determined to be 20

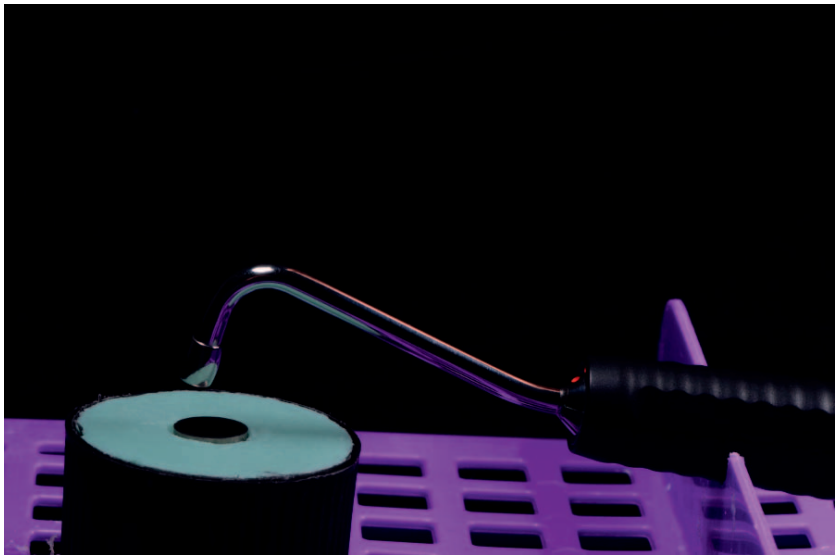

Figure 2. Ultraflex attached to the device. 


\begin{tabular}{|c|c|c|c|}
\hline \multicolumn{4}{|c|}{$\begin{array}{c}\text { TABLE } 1 \\
\text { Roughness average (Ra) of the } \mathrm{G} 1, \mathrm{G} 2 \text {, and } \mathrm{G} 3 \text { specimens* }\end{array}$} \\
\hline & $\begin{array}{c}\text { G1 Values Ra } \\
(\mu \mathrm{m})\end{array}$ & $\begin{array}{c}\text { G2 Values Ra } \\
(\mu \mathrm{m})\end{array}$ & $\begin{array}{c}\text { G3 Values Ra } \\
(\mu \mathrm{m})\end{array}$ \\
\hline Disk 1 & 0.096 & 0.176 & 0.15 \\
\hline Disk 2 & 0.122 & 0.272 & 0.061 \\
\hline Disk 3 & 0.145 & 0.28 & 0.1 \\
\hline Disk 4 & 0.137 & 0.178 & 0.083 \\
\hline Disk 5 & 0.063 & 0.156 & 0.2 \\
\hline Mean (DV) & $0.112 \pm 0.033$ & $0.212 \pm 0.058$ & $0.118 \pm 0.049$ \\
\hline
\end{tabular}

*G1 indicates water and air; G2, water, air, and sodium bicarbonate; G3, water, air, and glycine; DV, standard deviation.

seconds, was controlled with a stopwatch. Before and after the blasting, the specimens were submerged in $70 \%$ alcohol and placed for 180 seconds in an ultrasonic cleaning tank.

The roughness evaluation and analyses were performed by a blinded examiner (B.R.B.) using an optical profilometer (NewView 7100, Zygo, Middlefield, Conn) equipped with a precision lateral calibration standard able to determine a camera pixel-to-pixel spacing for lateral measurements for high precision automatic lateral calibration in order to characterize and quantify surface roughness without direct contact with the sample using light wavelength as a scale. A random computergenerated code associated the samples to the profilometry result; specifically, the average values of Ra were determined. Samples were stabilized on the apparatus table; 2 points were chosen for random analysis at the blasting site, and the mean $\mathrm{Ra}$ of each sample was obtained.

\section{Statistical evaluation}

Methodology and statistical evaluation were reviewed by the independent statistician (C.A.M.B.) using the statistical analysis software StatPlus6 (Analystsoft, Walnut, Calif). Differences between experimental groups were evaluated

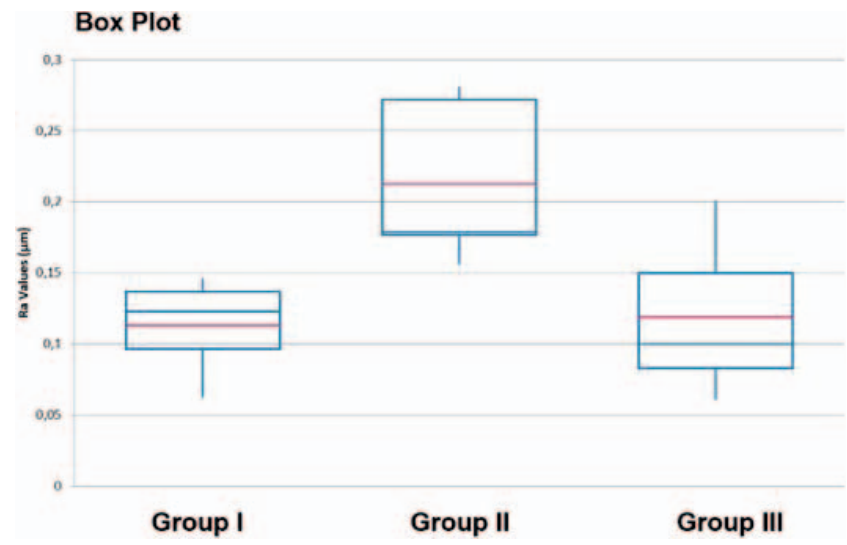

Figure 3. Groups box plot summary. Box $=25$ th and 75th percentile. Bars $=$ mean and maximum values of roughness average. Lines $=$ mean and median values

by one-way analysis of variance followed by the Tukey post hoc test. Differences of $P<.05$ were considered statistically significant.

\section{ReSULtS}

The Ra values for the 3 groups obtained by optical profilometry are shown in Table 1. The outcomes of descriptive statistical analysis are synthesized in Table 2 where, by comparing the means of Ra $(\mu \mathrm{m})$ of the groups, significant differences were found. Specifically, G2 samples presented statistically higher values of Ra compared with G1 (mean difference [MD] = $-0.09974 ; 95 \% \mathrm{Cl}=-0.1889$ to $-0.0105 ; P=.0107)$. In addition, the evaluation showed that there is also a statistically significant difference between the $\mathrm{G} 2$ and $\mathrm{G} 3$ groups (MD = $0.09374 ; 95 \% \mathrm{Cl}=0.0045$ to $0.1829 ; P=.0321$ ), while the comparative analysis between G1 and G3 groups showed no

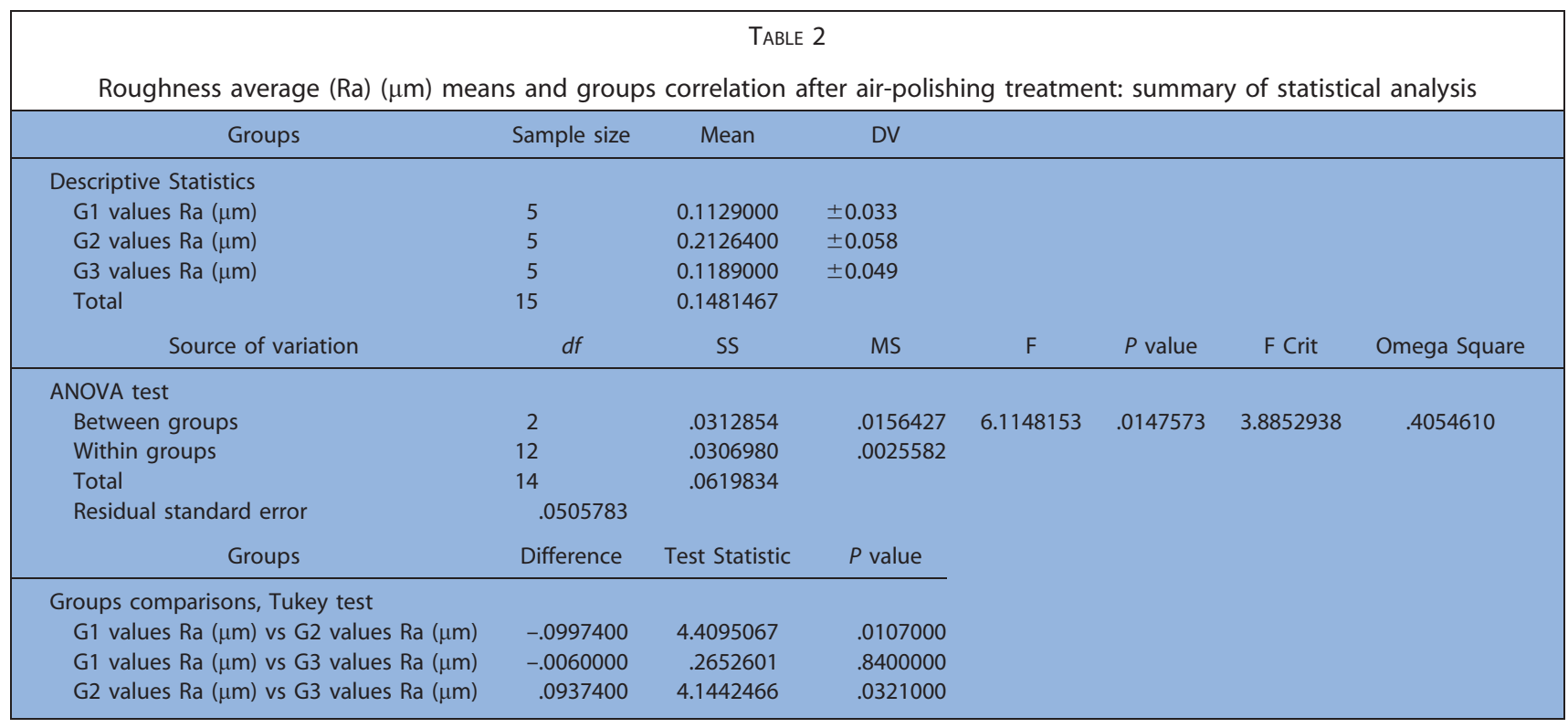

${ }^{*} \mathrm{G} 1$ indicates water and air; G2, water, air, and sodium bicarbonate; G3, water, air, and glycine; $d f$, degrees of freedom; ANOVA, analysis of variance; DV, standard deviation; SS, sum-of-squares; MS, mean squares; F, F ratio; F Crit, F critical. 
statistically significant differences $(\mathrm{MD}=-0.0060 ; 95 \% \mathrm{Cl}=-$ 0.0951 to $0.0831 ; P=.84$ ) (Figure 3).

\section{Discussion}

The outcome of the investigation supports rejection of the null hypothesis. The results of the present study suggest that sandblasting with sodium bicarbonate powder would be more damaging to the surface of prosthetic components and result in higher roughness values compared with glycine powder after 20 seconds of blasting. Therefore, a powder that shows less ability to roughen the surfaces is of great value. Glycine blasting does not seem to alter the titanium surface as its results were not statistically different from those obtained with the air and water group.

Also, Cochis et al ${ }^{7}$ showed significant differences and lower bacterial contamination of glycine powder treatment compared with the bicarbonate-treated group. This is associated with an increased roughness and the formation of craters.

In cases of patients with periodontal or peri-implant disease, there is an increasing need to study and develop alternatives for minimal traumatic prophylactic procedures. According to the present study, glycine would be the powder of choice. This finding is supported by clinical studies 2,10 indicating a greater patient acceptance of glycine powder as, unlike bicarbonate, it causes minimal injury and irritation to the periodontal tissues. Indeed, Petersilka et $\mathrm{al}^{20}$ proved that glycine caused fewer defects in subgingival application compared with the application of sodium bicarbonate powder. The use of glycine powder has been shown to be significantly more effective in reducing subgingival microflora in shallow periodontal pockets, even compared with the use of curettes, and is safe to apply to root surfaces. Newman et $\mathrm{al}^{21}$ stated that bicarbonate sandblasting in areas of periodontal disease is not recommended. For periodontal and peri-implant maintenance, the patient is subjected to prophylactic procedures with blasting devices periodically. Once lesions have been generated on the implant abutment surface, it should be taken into account that more prophylaxis will result in more topographic changes, which will facilitate future proliferation of bacteria and biofilm adherence to these structures. ${ }^{3}$

The experience of pain is seen as relevant in dental practice, and. according to Moëne et $\mathrm{al}^{22}$ patients reported minimal gingival irritation with the use of glycine and considered it to be significantly more comfortable than sodium bicarbonate powder. Horning et $\mathrm{al}^{23}$ pointed out patient discomfort with the salty taste of bicarbonate, while glycine is well accepted as it has a slightly sweet taste. In a recent literature review, ${ }^{24}$ it was concluded that the minimal gingival irritation caused by glycine powder is one of the factors that would place it as the first option in prophylactic procedures as the patient's perception and comfort are considered increasingly important in dental practice. Moreover, the use of glycine amino acid as prophylactic powder on any surfaces could also be an alternative for the use of oscillating or manual scrapers as it was demonstrated to be more effective in plaque removal compared with manual instrumentation. ${ }^{16}$ However, it must be considered that glycine-based powders can cost 3 times as much as sodium bicarbonate powders.
The present study provided an in vitro evaluation; therefore. It was an environment free of the characteristics related to the oral ecosystem; this aspect represents a determinant limit of this investigation. In the future, it would be interesting to better characterize and compare the roughness generated on implant surface using 3-dimensional spatial parameters, such as arithmetical mean height, at different application distances and polishing durations, as these aspects could influence titanium surface. It would also be useful to investigate cleaning efficacy and surface biocompatibility after glycine and sodium bicarbonate decontamination. Last, but not least, the relevance of the present results for clinical practice should be clinically investigated in an in vivo human study.

\section{Conclusions}

In conclusions, the present study suggests that the ability of glycine powder to generate roughness on the surface of implant titanium abutments is significantly lower than that of sodium bicarbonate in a prophylactic blasting procedure, according to the experimental conditions investigated.

\section{Abbreviations}

Ra: arithmetic average of the roughness profile

\section{Note}

The authors do not have any financial interests, either directly or indirectly, in the products or information listed in the paper.

\section{References}

1. Petersilka GJ. Subgingival air-polishing in the treatment of periodontal biofilm infections. Periodontol. 2000. 2011;55:124-142.

2. Mombelli A, Lang NP. Antimicrobial treatment of peri-implant infections. Clin Oral Implants Res. 1992;3:162-168.

3. Subramani K, Jung RE, Molenberg A, Hämmerle $\mathrm{CH}$. Biofilm on dental implants: a review of the literature. Int J Oral Maxillofac Implants. 2009;24:616-626.

4. Happe A, Röling N, Schäfer A, Rothamel D. Effects of different polishing protocols on the surface roughness of Y-TZP surfaces used for custom-made implant abutments: a controlled morphologic SEM and profilometric pilot study. J Prosthetic Dent. 2015;113:440-447.

5. Bollen CM, Papaioanno W, Van Eldere J, Schepers E, Quirynen M, Van Steenberghe $D$. The influence of abutment surface roughness on plaque accumulation and peri-implant mucositis. Clin Oral Implants Res. 1996;7:201211

6. Mombelli A. Critical issues in periodontal diagnosis. Periodontol. 2000. 2005;39:9-12.

7. Cochis A, Fini M, Carrassi A, Migliario M, Visai L, Rimondini L. Effect of air polishing with glycine powder on titanium abutment surfaces. Clin Oral Implants Res. 2013;24:904-909.

8. Menini M, Piccardo P, Baldi D, Dellepiane E, Pera P. Morphological and chemical characteristics of different titanium surfaces treated by bicarbonate and glycine powder air abrasive systems. Implant Dent. 2015;24: 47-56.

9. Schwarz F, Ferrari D, Popovski K, Hartig B, Becker J. Influence of different air-abrasive powders on cell viability at biologically contaminated titanium dental implants surfaces. J Biomed Mater Res Part B Appl Biomater. 2009;88:83-91. 
10. Giacomelli L, Salerno M, Derchi G, Genovesi A, Paolo Paganin P, Covani U. Effect of air polishing with glycine and bicarbonate powders on a nanocomposite used in dental restorations: an in vitro study. Int $J$ Periodontics Restorative Dent. 2011;31:545

11. Sahrmann P, Ronay V, Sener B, Jung RE, Attin T, Schmidlin PR. Cleaning potential of glycine air-flow application in an in vitro periimplantitis model. Clin Oral Implants Res. 2013;24:666-670.

12. Brookshire FVG, Nagy WW, Dhuru VB, Ziebert GJ, Chada S. The qualitative effects of various types of hygiene instrumentation on commercially pure titanium and titanium alloy implant abutments: an in vitro and scanning electron microscope study. J Prosthet Dent. 1997;78:286294.

13. Sygkounas E, Louropoulou A, Schoenmaker T, de Vries TJ, Van der Weijden FA. Influence of various air-abrasive powders on the viability and density of periodontal cells: an in vitro study. J Biomed Mater Res Part B Appl Biomater. 2018;106:1955-1963.

14. Shibli JA, Silverio KG, Martins MC, Marcantonio E Jr, Rossa C Jr. Effect of air-powder system on titanium surface on fibroblast adhesion and morphology. Implant Dent. 2003;12:81-86.

15. Petersilka G, Faggion CM, Stratmann U, et al. Effect of glycine powder air-polishing on the gingiva. J Clin Periodontol. 2008;35:324-332.

16. Riben-Grundstrom C, Norderyd O, André U, Renvert S. Treatment of peri-implant mucositis using a glycine powder air-polishing or ultrasonic device: a randomized clinical trial. J Clin Periodontol. 2015;42:462-469.
17. Chairay J-P, Boulekbache H, Jean A, Soyer A, Bouchard P. Scanning electron microscopic evaluation of the effects of an air-abrasive system on dental implants: a comparative in vitro study between machined and plasma-sprayed titanium surfaces. J Periodontol. 1997;68:1215-1222.

18. Sahm N, Becker J, Santel T, Schwarz F. Non-surgical treatment of peri-implantitis using an air-abrasive device or mechanical debridement and local application of chlorhexidine: a prospective, randomized, controlled clinical study. J Clin Periodontol. 2011;38:872-878.

19. Graumann SJ, Sensat ML, Stoltenberg JL. Air polishing: a review of current literature. J Dent Hyg. 2013;87:173-180.

20. Petersilka GJ, Bell M, Häberlein I, Mehl A, Hickel R, Flemmig TF. In vitro evaluation of novel low abrasive air polishing powders. J Clin Periodontol. 2003;30:9-13.

21. Newman PS, Silverwood RA, Dolby AE. The effects of an airbrasive instrument on dental hard tissues, skin and oral mucosa. Br Dent J. 1985;159: 9-12.

22. Moëne R, Décaillet F, Andersen E, Mombelli A. Subgingival plaque removal using a new air-polishing device. J Periodontol. 2010;81:79-88.

23. Horning GM, Cobb CM, Killoy WJ. Effect of an air-powder abrasive system on root surfaces in periodontal surgery. J Clin Periodontol. 1987;14: 213-220.

24. Bühler J, Amato $M$, Weiger $R$, Walter $C$. A systematic review on the effects of air polishing devices on oral tissues. Int J Dental Hyg. 2016;14:1528 
Copyright of Journal of Oral Implantology is the property of Allen Press Publishing Services Inc. and its content may not be copied or emailed to multiple sites or posted to a listserv without the copyright holder's express written permission. However, users may print, download, or email articles for individual use. 